\title{
Lipid profiles and ischemic stroke risk: variations by sex within racial/ethnic groups
}

This article was published in the following Dove Press journal:

International Journal of Women's Health

30 May 2014

Number of times this article has been viewed

\section{Tefera Gezmu' \\ Dona Schneider' \\ Kitaw Demissie ${ }^{2}$ \\ Yong Lin ${ }^{2}$ \\ Christine Giordano ${ }^{3}$ \\ Martin S Gizzi ${ }^{4}$ \\ 'Edward J. Bloustein School of Planning and Public Policy, Rutgers, the State University of New Jersey, \\ New Brunswick, NJ, ${ }^{2}$ Rutgers School of Public Health, Department of Epidemiology, Piscataway, NJ, ${ }^{3}$ Rutgers New Jersey Medical School, Newark, NJ, ${ }^{4}$ New Jersey Neuroscience Institute at JFK Medical Center and Seton Hall University, Edison, NJ, USA}

Correspondence:Tefera Gezmu Edward J. Bloustein School of Planning and Public Policy, Rutgers, the State University of New Jersey, Civic Square, 33 Livingston Avenue, Room 258 New Brunswick, NJ 0890I, USA

Tel +l 8489322756

Fax +l 7329326564

Email gezmu@rutgers.edu
Abstract: Evidence implicates lipid abnormalities as important but modifiable risk factors for stroke. This study assesses whether hypercholesterolemia can be used to predict the risk for etiologic subtypes of ischemic stroke between sexes within racial/ethnic groups. Data elements related to stroke risk, diagnosis, and outcomes were abstracted from the medical records of 3,290 acute stroke admissions between 2006 and 2010 at a regional stroke center. Sex comparison within racial/ethnic groups revealed that South Asian and Hispanic men had a higher proportion of ischemic stroke than women, while the inverse was true for Whites and African Americans $(P=0.0014)$. All women, except South Asian women, had higher mean plasma total cholesterol and higher blood circulating low-density lipoprotein levels ( $\geq 100 \mathrm{mg} / \mathrm{dL}$ ) than men at the time of their admissions. The incidence of large-artery atherosclerosis (LAA) was more common among women than men, except among Hispanics, where men tended to have higher incidences. A regression analysis that considered patients diagnosed with either LAA or small-artery occlusion etiologic subtype as the outcomes and high-density lipoproteins and triglycerides as predictors showed inconsistent associations between lipid profiles and the incidence of these subtypes between the sexes within racial/ethnic groups. In conclusion, our investigation suggests that women stroke patients may be at increased risk for stroke etiologic subtype LAA than men. Although the higher prevalence of stroke risk factors examined in this study predicts the increase in the incidence of the disease, lack of knowledge/awareness and lack of affordable treatments for stroke risk factors among women and immigrants/non-US-born subpopulations may explain the observed associations.

Keywords: ischemic stroke, risk factors, sex, race/ethnicity, cerebrovascular disease, comorbidities

\section{Background}

Stroke is the leading cause of long-term disability in the United States ${ }^{1}$ and ranks fourth among all causes of death, behind diseases of the heart, cancer, and chronic lower respiratory diseases. ${ }^{2-4}$ Stroke incidences also differ by sex, exhibiting the classical "female paradox" phenomenon; while the incidence of stroke is greater among men, women suffer worse outcomes from the disease. ${ }^{3,5}$ Several studies have highlighted this differential effect of sex on stroke. Di Carlo et $\mathrm{al}^{6}$ reported that women are $41 \%$ more likely to have worse disability following stroke than men. Moreover, some $60 \%$ of stroke deaths in 2008 occurred among women. ${ }^{1}$ Additional studies have also identified differences not only in the risk profiles between the sexes, but also between racial/ethnic groups. ${ }^{7-9}$

In considering sex differences in the incidence and mortality from stroke, some studies have reported a correlation between menopause, with its concomitant changes 
in arterial structure, and the worsening of biochemical risk factors for atherosclerosis. ${ }^{10-21}$ Others point to an increased prevalence of metabolic syndromes among menopausal women as responsible for the disparity in stroke between the sexes. ${ }^{12}$ Increasing evidence implicates dyslipidemia and elevated triglycerides and total cholesterol (TC) levels as important but modifiable risk factors for stroke. ${ }^{2,13}$

The association between higher levels of triglycerides and stroke, however, is tenuous at best. ${ }^{14,15}$ Interpreting the relationship between TC and stroke is often confounded by the type of stroke under consideration (ischemic versus hemorrhagic). The MR FIT (Multiple Risk Factor Intervention Trial) showed that the risk for hemorrhagic stroke was inversely related to TC levels; however, risk for ischemic stroke increased as TC levels exceeded $200 \mathrm{mg} / \mathrm{dL}$. In fact, the risk for ischemic stroke more than doubled when TC levels exceeded $280 \mathrm{mg} / \mathrm{dL} .{ }^{16}$ Similar results were shown in a health maintenance organization-based case-control study by Tirschwell et al, ${ }^{17}$ which reported an increased risk of certain subtypes of ischemic stroke with higher TC and lower high-density lipoprotein (HDL) levels. However, only a few prospective studies with racially/ethnically diverse populations have examined the associations between the subtypes of ischemic stroke and lipid abnormalities such as hypercholesterolemia (high levels of TC and triglycerides). ${ }^{18,19}$

Because of the increasing diversity and aging of the US population, identification of specific risk factors for each racial/ethnic group by sex may help further improve outcomes following stroke. Such information may even help devise practical preventive and interventional approaches to stroke care in these subpopulations. In this study, we examined the impact and prognostic influence of stroke risk factors at the time of stroke admission. We evaluated lipid profiles, specifically the severity of hypercholesterolemia and triglyceride levels, in predicting the risk for the subtypes of ischemic stroke between the sexes and within the different racial/ethnic groups in a large cohort of hospitalized stroke patients.

\section{Methods}

Data on acute stroke admissions was prospectively collected at a comprehensive stroke center serving a racially/ethnically diverse population in Northern New Jersey. All data elements related to stroke diagnosis, treatment, and outcomes were abstracted from the medical records by trained personnel using a fixed algorithm and entered into a computerized registry system. These data included all elements of Center for Disease Control's Coverdell registry, including the National
Institutes of Health Stroke Scale scoring system for severity of outcome and the Trial of ORG 10172 in Acute Stroke Treatment (TOAST) for etiologic classifications of ischemic stroke. $^{20}$

\section{Study populations}

A total of 3,290 acute stroke admissions between 2006 and 2010 who met the racial/ethnic criteria (White, African American, South Asian, or Hispanic) and were $\geq 18$ years of age were selected for this analysis. A surname method of racial/ethnic classification, a validated method that has been used in several previous studies, including the US Census Bureau among others, ${ }^{21-24}$ was used to identify subjects in the South Asian race/ethnicity category.

\section{Stroke subtypes}

All subjects had computed tomography (CT) scans of the brain at the time of initial evaluation and again in 24 hours. The majority of patients also underwent magnetic resonance (MR) imaging of the brain. Some patients had extracranial vascular imaging using CT angiography and MR angiography. The remainder of the patients underwent carotid duplex ultrasound. Patients undergoing CT angiography or MR angiography also had intracranial vascular imaging, as well as two-dimensional trans-thoracic echocardiography. In addition, those with a strong suspicion for an embolic source underwent trans-esophageal imaging. Patients also underwent either Holter monitoring or a minimum of 24 hours of telemetric cardiac monitoring. A stroke-trained neurologist performed the TOAST criteria for the etiologic classifications of ischemic stroke. Of 3,290 acute stroke admissions, 47\% $(1,541)$ were diagnosed as ischemic stroke and were selected for the TOAST classification as either large-artery atherosclerosis (LAA), cardioembolism (CE), small-artery occlusion (SAO), other determined/known cause, and undetermined/ unknown causes (including two or more of the above). ${ }^{20,25}$ For this analysis, we combined the last two categories.

\section{Stroke risk factors}

The following vascular risk factors were evaluated: age, sex, and history of hypertension, diabetes mellitus, dyslipidemia, and smoking (any smoking within a year prior to admission). Test results of systolic/diastolic blood pressures, fasting blood glucose, glycated hemoglobin $\left(\mathrm{HbA}_{1 \mathrm{c}}\right)$, lipids (TC, HDL/low-density lipoprotein [LDL], and triglycerides) and coagulation profiles were completed both upon admission and within 48 hours following admission for acute stroke. Additional variables collected 
included any current treatment with antihypertensives, diabetic medications, or cholesterol-reducing medications. Following the criteria for classification in diagnosis of diabetes by the American Diabetes Association, ${ }^{26}$ we conducted a separate analysis to examine plasma TC levels using the following categories (where $\mathrm{TC}<200 \mathrm{mg} / \mathrm{dL}=$ desirable, $\mathrm{TC}=200-239 \mathrm{mg} / \mathrm{dL}=$ borderline high, and $\mathrm{TC}>240 \mathrm{mg} / \mathrm{dL}=$ high). Furthermore, we examined the conflicting evidence ${ }^{27}$ that an overall high level of LDL is a potent risk factor for the incidence of stroke, by examining the extent to which acute stroke patients in our cohort had LDL cholesterol (LDL-c) levels $\geq 100 \mathrm{mg} / \mathrm{dL}$ within the first 48 hours after their hospital arrival or 30 days prior to their stroke admissions.

\section{Statistical analysis}

A two-part analysis was carried out. The first part focused on the entire cohort of stroke admissions and assessed socio-demographic variables, the prevalence of stroke risk factors, and clinical profiles by sex within racial/ ethnic group. Summary data are expressed as means \pm standard deviations for interval data and as proportions for categorical variables. Because triglycerides, $\mathrm{HbA}_{1 \mathrm{c}}$, and fasting blood glucose values were positively skewed, natural logarithmic transformation was used, and results were expressed as geometric means with $95 \%$ confidence intervals (CIs). Testing for differences between sexes within racial/ethnic groups was done using the chi-square test (or Fisher's exact test for small cell counts) for categorical variables and analysis of variance for interval measures.

In the second part of the analysis, a regression model was fitted with ischemic stroke etiologic subtypes LAA and SAO as dependent variables and patient lipid profiles (TC, HDL, and triglycerides), age, history of smoking, and history of dyslipidemia as independent variables to predict the risk of developing LAA versus SAO by sex within a racial/ethnic group. The regression model fitted was a "modified Poisson" approach with "sandwich error estimation" using the SAS PROC GENMOD procedure with REPEATED statement (patient ID, in our data) fitted to estimate (the relative risk [RR] and 95\% CIs) for the probability of developing large vessel disease (LAA versus SAO) after adjusting for several confounding factors. All analyses were carried out using SAS statistical software, version 9.2 (SAS Institute Inc., Cary, NC, USA). Results were considered significant if $P<0.05$. Institutional Review Board approval to evaluate the stroke registry data for this project was obtained both from the JFK
Medical Center and the University of Medicine and Dentistry of New Jersey.

\section{Results}

Patient characteristics and clinical measurements at the time of admission are detailed in Table 1. Stroke admissions were less common among South Asian and Hispanic women (40.7\% and 46.9\%, respectively) as compared with their male counterparts; however, the inverse was true for Whites and African Americans. White women were significantly older than their male counterparts (75.3 versus 70.3 , respectively; $P<0.0001)$, but no significant age differences were observed between the sexes of the remaining racial/ ethnic groups.

For all racial/ethnic groups except South Asians, females had higher mean plasma TC levels than their male counterparts. The largest difference by sex was observed among African Americans, where the average TC levels among women were $18.1 \mathrm{mg} / \mathrm{dL}$ points higher than that of men $(P<0.0001)$ (Table 1). The difference in TC can be partially explained by the fact that women had statistically significantly higher HDL levels than men $(P=0.001)$. LDL levels within most racial/ethnic groups were also higher among women; only South Asian women had lower LDL plasma concentration levels than their male counterparts (Table 1). Overall, females had a slightly higher mean body mass index (BMI in $\mathrm{kg} / \mathrm{m}^{2}$ ) than males, except among Whites, where male stroke patients were significantly heavier than females $(P=0.0059)$. None of the by-sex comparisons of triglycerides, blood pressure, $\mathrm{HbA}_{1 \mathrm{c}}$, and fasting blood glucose levels were found to be statistically significantly different. We also found that examination of plasma TC levels by the categories showed that patients with TC plasma levels $>240 \mathrm{mg} / \mathrm{dL}$, where the risk for coronary artery disease is considered to be greatest, were consistently higher among females than males. We have also noticed inconsistent trends for other clinical characteristics of study subjects; we have provided the details of our findings in this regard in Table S1 for reference.

Examination of the extent to which acute stroke patients in our cohort had LDL-c levels $\geq 100 \mathrm{mg} / \mathrm{dL}$ within the first 48 hours after their hospital arrival or 30 days prior to their stroke admissions showed that women of all racial/ethnic groups, except for the South Asians, had higher likelihood of having LDL-c levels that are $\geq 100 \mathrm{mg} / \mathrm{dL}$ on admission than their male counterparts (Table 2). The proportion of patients who had prescriptions for cholesterol reducing medications (statins) at the time of their admission and at discharge were higher among White and African American females, while 
Table I Characteristics of patients with acute stroke on admission, by sex within racial/ethnic groups

\begin{tabular}{|c|c|c|c|c|}
\hline \multirow[t]{2}{*}{ Characteristic } & \multicolumn{4}{|l|}{ Race/ethnicity } \\
\hline & $\begin{array}{l}\text { White } \\
(n=2,156)\end{array}$ & $\begin{array}{l}\text { African American } \\
(\mathrm{n}=605)\end{array}$ & $\begin{array}{l}\text { South Asian } \\
(n=273)\end{array}$ & $\begin{array}{l}\text { Hispanic } \\
(n=256)\end{array}$ \\
\hline Female, $\%$ a & 55.0 & 59.7 & 40.7 & 46.9 \\
\hline \multicolumn{5}{|c|}{ Mean age in years $( \pm S D)$} \\
\hline Male & $70.3(14.2)$ & $64.3(13.2)$ & $64.5(13.8)$ & $62.8(14.7)$ \\
\hline Female & $75.3(14.2)$ & $64.9(15.4)$ & $66.0(15.6)$ & $65.1(17.4)$ \\
\hline$P$-value ${ }^{\mathrm{a}}$ & $<0.0001$ & NS & NS & NS \\
\hline \multicolumn{5}{|c|}{ Clinical measurements on admission } \\
\hline \multicolumn{5}{|c|}{ Mean TC in $\mathrm{mg} / \mathrm{dL}( \pm \mathrm{SD})^{\mathrm{b}}$} \\
\hline Male & $165.2(42.9)$ & $166.6(48.3)$ & $172.8(44.2)$ & $171.2(54.3)$ \\
\hline Female & $176.9(45.2)$ & $184.7(45.2)$ & $171.5(46.1)$ & I83.I (45.0) \\
\hline$P$-value ${ }^{b, c}$ & $<0.0001$ & $<0.0001$ & NS & NS \\
\hline \multicolumn{5}{|c|}{ Mean HDL in $\mathrm{mg} / \mathrm{dL}( \pm \mathrm{SD})^{\mathrm{b}}$} \\
\hline Male & $39.6(11.3)$ & $40.7(14.4)$ & $39.4(11.6)$ & $38.3(11.5)$ \\
\hline Female & $46.6(14.6)$ & $48.1(15.0)$ & $44.5($ (II.8) & $43.7(10.4)$ \\
\hline$P$-value ${ }^{b, c}$ & $<0.0001$ & $<0.0001$ & 0.0010 & 0.0006 \\
\hline \multicolumn{5}{|c|}{ Mean LDL in $\mathrm{mg} / \mathrm{dL}( \pm \mathrm{SD})^{\mathrm{b}}$} \\
\hline Male & $101.8(37.1)$ & I03.I (38.3) & $108.4(37.4)$ & I I $0.4(44.3)$ \\
\hline Female & $106.1(39.6)$ & $115.9(38.5)$ & $101.5(39.1)$ & $112.1(36.1)$ \\
\hline$P$-value ${ }^{b, c}$ & 0.0177 & 0.0006 & NS & NS \\
\hline \multicolumn{5}{|c|}{ Mean systolic blood pressure in $\mathrm{mmHg}( \pm \mathrm{SD})$} \\
\hline Male & I50.I (28.3) & $153.5(32.2)$ & $153.8(31.9)$ & $149.6(27.6)$ \\
\hline Female & $154.8(32.1)$ & $154.0(32.1)$ & $161.6(33.3)$ & I54.I (28.8) \\
\hline$P$-value ${ }^{c}$ & 0.0006 & NS & NS & NS \\
\hline \multicolumn{5}{|c|}{ Mean diastolic blood pressure in $\mathrm{mmHg}( \pm \mathrm{SD})^{\mathrm{b}}$} \\
\hline Male & $83.1(17.8)$ & $87.3(21.2)$ & $87.1(18.1)$ & $83.3(16.3)$ \\
\hline Female & $82.4(19.4)$ & $85.4(19.3)$ & $88.0(25.2)$ & $82.5(18.3)$ \\
\hline \multicolumn{5}{|c|}{ Mean body mass index in $\mathrm{kg} / \mathrm{m}^{2}( \pm \mathrm{SD})^{\mathrm{b}}$} \\
\hline Male & $27.7(5.5)$ & $28.0(6.4)$ & $25.4(4.3)$ & $27.9(4.3)$ \\
\hline Female & $27.1(6.3)$ & $29.8(7.5)$ & $26.5(5.8)$ & $28.8(7.0)$ \\
\hline$P$-value ${ }^{c}$ & 0.0059 & 0.0029 & NS & NS \\
\hline \multicolumn{5}{|c|}{ Geometric mean fasting blood glucose in $\mathrm{mg} / \mathrm{dL}(95 \% \mathrm{Cl})^{\mathrm{b}}$} \\
\hline Male & $125.0(122.3-127.8)$ & $126.9(|20.7-| 33.5)$ & $126.5(\mid 19.3-134.1)$ & $128.5(\mid 20.4-137.2)$ \\
\hline Female & $119.7(117.4-121.9)$ & $126.5(|2| .3-13 \mid .8)$ & | $38.2(|27.6-| 49.8)$ & $128.5(119.3-138.4)$ \\
\hline \multicolumn{5}{|c|}{ Geometric mean $\mathrm{HbA}_{\mathrm{lc}}$ in $\%(95 \% \mathrm{Cl})^{\mathrm{b}}$} \\
\hline Male & $6.3(6.2-6.4)$ & $6.5(6.3-6.7)$ & $6.8(6.5-7.0)$ & $6.4(6.2-6.7)$ \\
\hline Female & $6.2(6.1-6.3)$ & $6.5(6.4-6.7)$ & $6.9(6.6-7.2)$ & $6.4(6.1-6.6)$ \\
\hline \multicolumn{5}{|c|}{ Geometric mean triglycerides in $\mathrm{mg} / \mathrm{dL}(95 \% \mathrm{Cl})^{\mathrm{b}}$} \\
\hline Male & $107.6(103.9-111.3)$ & $92.9(86.1-100.3)$ & $115.9(106.3-126.4)$ & $107.9(94.5-123.1)$ \\
\hline Female & $107.4(104.2-110.6)$ & $91.6(86.5-97.0)$ & II $5.6(104.0-128.4)$ & $117.2(106.3-129.2)$ \\
\hline
\end{tabular}

Notes: ${ }^{a} \chi^{2}$ test $P<0.000$ I. bStatistical test did not include missing values $\left(\sim 12 \%-17 \%\right.$ for TC, LDL/HDL and $35 \%$ for $\left.\mathrm{HbA}_{1}\right)$; also $P$-values for variables that were not statistically significantly different by sex are not shown. 'Analysis of variance for comparing means.

Abbreviations: $\mathrm{Cl}$, confidence interval; $\mathrm{HbA}_{\mathrm{lc}}$, glycated hemoglobin; $\mathrm{HDL}$, high-density lipoprotein; $\mathrm{LDL}$, low-density lipoprotein; $\mathrm{NS}$, not significant at $P=0.05$ level; $\mathrm{SD}$, standard deviation; TC, total cholesterol.

South Asian and Hispanic males had higher frequencies of these prescriptions (Table 2).

Similarly, White and African American females were more likely to be on medications for hypertension or diabetes, and on anticoagulation at the time of admission than their male counterparts, while the reverse relationship was found within Hispanic and South Asian patients (Table 3). Stroke risk factors such as hypertension, diabetes mellitus, cardiac diseases, dyslipidemia, and previous history of stroke/tran- sient ischemic attack (TIA) were more prevalent among South Asian and Hispanic men than women (Table 3). Histories of cigarette smoking were statistically significantly higher among males than females of all racial/ethnic groups. The largest difference in the proportion of smoking were seen among South Asians, where the proportion of smoking was substantially higher among men than women $(P=0.0005)$.

The final diagnosis (type of stroke) for acute stroke admissions between the sexes within the racial/ethnic groups 
Table 2 Percentage severity of hypercholesterolemia and lipid profiles for acute stroke patients, by sex within racial/ethnic groups

\begin{tabular}{|c|c|c|c|c|c|}
\hline & \multicolumn{4}{|c|}{ Race/ethnicity $(\mathrm{N}=3,290)$} & \multirow[t]{2}{*}{$P$-value } \\
\hline & White & African American & South Asian & Hispanic & \\
\hline \multicolumn{6}{|c|}{ LDL-c level on admission $\geq 100 \mathrm{mg} / \mathrm{dL}, \%^{\mathrm{b}}$} \\
\hline Yes $(n=1,346)$ & 47.9 & 57.9 & 52.8 & 56.2 & 0.0003 \\
\hline Male & 42.6 & 36.2 & 63.6 & 48.7 & \\
\hline Female & 57.4 & 63.8 & 36.4 & 51.3 & \\
\hline No $(n=1,299)$ & 52.1 & 42.1 & 47.2 & 43.8 & \\
\hline$P$-value ${ }^{c}$ & 0.0462 & 0.0111 & NS & NS & \\
\hline \multicolumn{6}{|c|}{ Cholesterol reducers on admission, \% ${ }^{d}$} \\
\hline Yes $(n=1,394)$ & 45.0 & 37.3 & 37.5 & 38.3 & 0.0007 \\
\hline Male & 48.3 & 43.1 & 61.8 & 53.1 & \\
\hline Female & 51.7 & 56.9 & 38.2 & 46.9 & \\
\hline No $(n=1,890)$ & 55.0 & 62.8 & 62.5 & 61.7 & \\
\hline$P$-value ${ }^{c}$ & 0.0058 & NS & NS & NS & \\
\hline \multicolumn{6}{|c|}{ Cholesterol reducers at discharge, $\%$} \\
\hline Statin $(n=1,852)^{e}$ & 55.0 & 60.5 & 65.6 & 59.2 & 0.0027 \\
\hline Male & 47.4 & 40.2 & 64.5 & 56.7 & \\
\hline Female & 52.6 & 59.8 & 35.5 & 43.3 & \\
\hline$P$-value & 0.0076 & NS & 0.0325 & NS & \\
\hline Other medications & 1.2 & 0.8 & 0.4 & 1.2 & \\
\hline Contraindicated & 5.4 & 3.8 & 4.0 & 7.0 & \\
\hline None prescribed & 37.3 & 34.1 & 31.3 & 28.6 & \\
\hline
\end{tabular}

Notes: ${ }^{\mathrm{a}} \chi^{2}$ test for differences between racial/ethnic groups; ${ }^{\mathrm{b}} 19.6 \%$ data missing; ${ }^{\mathrm{c}} \chi^{2}$ test differences between the sexes within a racial/ethnic group; ${ }^{\text {dess }}$ than $0.2 \%$ ( $\mathrm{n}=6$ ) data missing; eabout 6\% data missing.

Abbreviations: LDL-c, low-density lipoprotein cholesterol; NS, not significant at $P<0.05$ level.

are detailed in Table 4. Among patients with the incidence of ischemic stroke, South Asians (58.8\%) and Hispanics (52.4\%) had higher proportions of men than women with ischemic stroke diagnosis, while the inverse was true among White and African Americans. Although similar trends were observed among those diagnosed with TIA and subarachnoid hemorrhage, the incidences of intracerebral hemorrhage were consistently higher among males of all racial/ethnic groups albeit not statistically significantly so (Table 4). A closer examination of patients with only ischemic stroke diagnoses $(\mathrm{n}=1,541)$ reveals that the LAA subtype was more common among women of all racial/ethnic groups except Hispanics, where Hispanic men had a higher proportion of patients with this etiologic subtype (Table 4). Similarly, and consistent with previous studies ${ }^{28}$ the incidence of SAO was more common among women than men, except among South Asians, where men tended to have a higher rate of diagnosis of this subtype when compared by sex. The biggest difference in the sex comparison for $\mathrm{CE}$ was observed among South Asians, where men were almost four times as likely to have $\mathrm{CE}$ diagnosis as compared with women (Table 4).

In the second part of the analysis, we examined the extent to which stroke risk factors (history of hypertension, diabetes mellitus, smoking, and dyslipidemia, as well as blood levels of LDL, HDL, and triglycerides as measures of hypercholesterolemia) are associated with the risk of the specific ischemic stroke subtypes (LAA and SAO) between the sexes and within racial/ethnic groups. The details for the logistic regression analysis by sex within a racial/ethnic group are detailed in Table 5. This analysis revealed that age was a statistically significant predictor for the increased risk of developing LAA among South Asian and White women. For every 10-year increase in age, South Asian woman had a $27 \%(\mathrm{RR}=1.27,95 \%$ CI 1.02-1.58) increased risk of developing LAA versus SAO. Likewise, White women had a $20 \%(\mathrm{RR}=1.20,95 \%$ CI 1.06-1.37) increased risk. This may be because women are more likely to suffer from SAO at younger ages; and thus, those without the incidence of SAO are effectively at increased risk for developing LAA as they advance in age. The same increase in age also raised the risk for LAA among African American men by $22 \%$ ( $R R=1.22,95 \%$ CI 1.05-1.41). Similarly, raised risks for LAA were also observed among Hispanic men and women, albeit not statistically significantly (Table 5). White women who reported a history of smoking were $82 \%$ more likely to develop LAA as opposed to SAO ( $\mathrm{RR}=1.82,95 \% \mathrm{CI}$ 1.36-2.45); although the risk for the development of LAA (versus SAO) was raised among White and African American men with history of smoking, this association did not meet statistical significance at the $P=0.05$ level. Moreover, due 
Table 3 Proportion of prescription medication use and the prevalence of most common stroke risk factors prior to admission, by sex within racial/ethnic groups

\begin{tabular}{|c|c|c|c|c|}
\hline & \multicolumn{4}{|c|}{ Race/ethnicity } \\
\hline & $\begin{array}{l}\text { White } \\
(n=2,156)\end{array}$ & $\begin{array}{l}\text { African } \\
\text { American } \\
(n=605)\end{array}$ & $\begin{array}{l}\text { South } \\
\text { Asian } \\
(n=273)\end{array}$ & $\begin{array}{l}\text { Hispanic } \\
(n=256)\end{array}$ \\
\hline \multicolumn{5}{|c|}{ History of prescription medication use } \\
\hline \multicolumn{5}{|c|}{ Antihypertensive medications, \% } \\
\hline Male & 42.7 & 40.7 & 58.8 & 54.1 \\
\hline Female & 57.3 & 59.3 & 41.2 & 45.9 \\
\hline$P$-value ${ }^{a}$ & 0.0003 & NS & NS & NS \\
\hline \multicolumn{5}{|c|}{ Cholesterol-reducing medications, \% } \\
\hline Male & 48.3 & 43.1 & 61.8 & 53.1 \\
\hline Female & 51.7 & 56.9 & 38.2 & 46.9 \\
\hline$P$-value ${ }^{\mathrm{a}}$ & 0.0060 & NS & NS & NS \\
\hline \multicolumn{5}{|c|}{ Antiplatelet medications, \% ${ }^{\mathrm{b}}$} \\
\hline Male & 45.1 & 38.8 & 63.4 & 57.6 \\
\hline Female & 54.9 & 61.2 & 36.6 & 42.4 \\
\hline \multicolumn{5}{|c|}{ Anticoagulant medications, \% } \\
\hline Male & 44.9 & 41.0 & 63.5 & 41.7 \\
\hline Female & 55.1 & 59.0 & 36.5 & 58.3 \\
\hline$P$-value ${ }^{\mathrm{a}}$ & NS & NS & NS & 0.0216 \\
\hline \multicolumn{5}{|c|}{ Diabetic medications, \% } \\
\hline Male & 47.2 & 39.9 & 61.1 & 54.3 \\
\hline Female & 52.8 & 60.1 & 38.9 & 45.7 \\
\hline \multicolumn{5}{|c|}{ Prevalence of most common stroke risk factors } \\
\hline \multicolumn{5}{|c|}{ Hypertension, \% } \\
\hline Male & 43.8 & 40.5 & 58.3 & 53.6 \\
\hline Female & 56.2 & 59.5 & 41.7 & 46.4 \\
\hline$P$-value ${ }^{\mathrm{a}}$ & 0.0362 & NS & NS & NS \\
\hline \multicolumn{5}{|c|}{ Diabetes mellitus, \% } \\
\hline Male & 48.7 & 41.2 & 57.3 & 50.6 \\
\hline Female & 51.4 & 58.8 & 42.7 & 49.4 \\
\hline$P$-value ${ }^{a}$ & 0.0287 & NS & NS & NS \\
\hline \multicolumn{5}{|c|}{ Cardiac disease, $\%$} \\
\hline Male & 47.0 & 43.8 & 68.7 & 59.7 \\
\hline Female & 53.0 & 56.2 & 31.3 & 40.3 \\
\hline \multicolumn{5}{|c|}{ Dyslipidemia, \% } \\
\hline Male & 48.0 & 38.2 & 65.0 & 50.0 \\
\hline Female & 52.0 & 61.8 & 35.0 & 50.0 \\
\hline$P$-value ${ }^{a}$ & 0.0374 & NS & NS & NS \\
\hline \multicolumn{5}{|c|}{ Smoking history, \% } \\
\hline Male & 58.0 & 55.9 & 92.0 & 76.2 \\
\hline Female & 42.0 & 44.1 & 8.0 & 23.8 \\
\hline$P$-value ${ }^{\mathrm{a}}$ & $<0.0001$ & 0.0009 & 0.0005 & 0.0271 \\
\hline \multicolumn{5}{|c|}{ Previous stroke/TIA d } \\
\hline Male & 47.5 & 39.0 & 61.2 & 50.7 \\
\hline Female & 52.5 & 61.0 & 38.2 & 49.3 \\
\hline \multicolumn{5}{|c|}{ Any combination ${ }^{\mathrm{e}}$} \\
\hline Male & 41.9 & 41.6 & 56.0 & 54.3 \\
\hline Female & 58.1 & 58.4 & 44.0 & 45.7 \\
\hline$P$-value ${ }^{a}$ & 0.0045 & NS & NS & NS \\
\hline
\end{tabular}

Notes: ${ }^{a} \chi^{2}$ test for differences between racial/ethnic groups; ${ }^{\text {iff }} P$-values for statistical test were entirely not statistically significantly different by sex within racial/ethnic groups they were omitted from the table; 'cardiac disease includes atrial fibrillation, prost heart valve, coronary artery disease/prior myocardial infarction, carotid stenosis, peripheral vascular diseases, and heart failure; ' ${ }^{\mathrm{T} I \mathrm{~A}}$ duration $<24$ hours; eany combination of these risk factors.

Abbreviations: NS, not significant at $P<0.05$ level; prost, prosthetic; TIA, transient ischemic attack.
Table 4 Percentages of clinical diagnosis related to acute stroke, by sex within racial/ethnic groups ${ }^{\mathrm{a}}$

\begin{tabular}{|c|c|c|c|c|}
\hline \multirow[t]{2}{*}{ Diagnosis } & \multicolumn{4}{|c|}{ Race/ethnicity ${ }^{\mathrm{b}}$} \\
\hline & $\begin{array}{l}\text { White } \\
(n=2,156)\end{array}$ & $\begin{array}{l}\text { African } \\
\text { American } \\
(n=605)\end{array}$ & $\begin{array}{l}\text { South } \\
\text { Asian } \\
(n=273)\end{array}$ & $\begin{array}{l}\text { Hispanic } \\
(n=256)\end{array}$ \\
\hline \multicolumn{5}{|c|}{ Ischemic stroke $(n=|, 54|)^{c, d}$} \\
\hline Male & 44.0 & 40.4 & 58.8 & 52.4 \\
\hline Female & 56.0 & 59.6 & 41.2 & 47.6 \\
\hline \multicolumn{5}{|c|}{ Large artery atherosclerosis $(n=360)$} \\
\hline Male & 42.3 & 48.3 & 44.4 & 56.3 \\
\hline Female & 57.7 & 51.7 & 55.6 & 43.7 \\
\hline \multicolumn{5}{|c|}{ Small artery occlusions $(n=354)$} \\
\hline Male & 47.1 & 31.8 & 52.5 & 44.0 \\
\hline Female & 52.9 & 68.2 & 47.5 & 56.0 \\
\hline \multicolumn{5}{|c|}{ Cardioembolism $(\mathrm{n}=26 \mathrm{I})$} \\
\hline Male & 43.5 & 61.8 & 81.8 & 50.0 \\
\hline Female & 56.5 & 38.2 & 18.2 & 50.0 \\
\hline \multicolumn{5}{|c|}{ Stroke of other determined and undetermined causes $(n=547)$} \\
\hline Male & 42.8 & 36.3 & 68.8 & 55.2 \\
\hline Female & 57.2 & 65.7 & 31.3 & 44.8 \\
\hline \multicolumn{5}{|c|}{$\operatorname{TIA}^{\mathrm{e}}(\mathrm{n}=\mathrm{I}, 179)$} \\
\hline Male & 44.5 & 35.8 & 61.5 & 51.1 \\
\hline Female & 55.5 & 64.2 & 38.5 & 48.9 \\
\hline \multicolumn{5}{|c|}{ Subarachnoid hemorrhage $(n=129)$} \\
\hline Male & 36.6 & 44.0 & 50.0 & 57.1 \\
\hline Female & 63.4 & 56.0 & 50.0 & 42.9 \\
\hline \multicolumn{5}{|c|}{ Intracerebral hemorrhage $(n=380)$} \\
\hline Male & 52.2 & 54.2 & 58.3 & 55.9 \\
\hline Female & 47.8 & 45.8 & 41.7 & 44.1 \\
\hline \multicolumn{5}{|c|}{ Stroke not otherwise specified $(n=23)$} \\
\hline Male & 42.9 & 50.0 & 100.0 & 100.0 \\
\hline Female & 57.1 & 50.0 & 0.0 & 0.0 \\
\hline \multicolumn{5}{|c|}{ No stroke-related diagnosis $(n=2 I)$} \\
\hline Male & 75.0 & 0.0 & 50.0 & 75.0 \\
\hline Female & 25.0 & 100.0 & 50.0 & 25.0 \\
\hline
\end{tabular}

Notes: a'Less than $0.5 \%$ of data was missing; ${ }^{b} \chi^{2}$ test for differences between sexes within a racial/ethnic group; 'ischemic stroke subtyping, based on classification scheme from the Trial of ORG 10172 in Acute Stroke Treatment (TOAST); dapproximately $1.2 \%$ of the data of ischemic stroke patients lacked subtyping information; ${ }^{\mathrm{e}}$ IIA duration $<24$ hours.

Abbreviation: TIA, transient ischemic attack.

to the very small number of women who have reported any history of smoking among South Asian and Hispanics, smoking was dropped from the regression analysis for these two racial/ethnic groups.

The assessment of hypercholesterolemia at the time of admission for acute stroke showed that only HDL and triglycerides resulted in marginally significant correlation with the risk of developing LAA (as opposed to SAO) in this cohort. A $10 \mathrm{mg} / \mathrm{dL}$ increase in the blood plasma levels of HDL reduced the risk for developing LAA among African American men by $25 \%$ ( $R R=0.75,95 \%$ CI $0.61-0.93$ ) and White women by $12 \%$ ( $R R=0.88,95 \%$ CI $0.80-0.96)$ (Table 5). On the other hand, plasma triglyceride levels did 
Table 5 Relative risk, stroke risk factors as predictors of ischemic stroke subtypes, ${ }^{a}$ by sex within racial/ethnic groups

\begin{tabular}{|c|c|c|c|c|}
\hline \multirow[t]{2}{*}{ Variable } & \multicolumn{4}{|c|}{ Relative risk $(95 \% \mathrm{CI})$} \\
\hline & White & African American & South Asian & Hispanic \\
\hline \multicolumn{5}{|c|}{ Age (per 10 years) } \\
\hline Male & $0.98(0.87-1.11)$ & $1.22(I .05-1.4 I)$ & $0.83(0.58-1.17)$ & $1.13(0.86-1.49)$ \\
\hline Female & $1.20(1.06-1.37)$ & $0.98(0.76-1.26)$ & $1.27(1.02-1.58)$ & $1.20(0.93-1.55)$ \\
\hline \multicolumn{5}{|c|}{ Smoking $($ Yes $=\mathrm{I}, \mathrm{No}=0)$} \\
\hline Male & $1.03(0.73-1.46)$ & $0.98(0.51-1.88)$ & $-{ }^{\mathbf{b}}$ & $-^{c}$ \\
\hline Female & $1.82(1.36-2.45)$ & $1.01(0.33-3.15)$ & - & - \\
\hline \multicolumn{5}{|c|}{ HDL (per 10 mg/dL) } \\
\hline Male & $0.91(0.78-1.05)$ & $0.75(0.61-0.93)$ & $0.62(0.35-1.09)$ & $1.09(0.92-1.30)$ \\
\hline Female & $0.88(0.80-0.96)$ & $1.06(0.95-1.18)$ & $0.93(0.74-1.18)$ & $1.01(0.73-1.40)$ \\
\hline \multicolumn{5}{|c|}{ Triglycerides (per 10 mg/dL) } \\
\hline Male & $0.99(0.97-1.01)$ & $0.94(0.88-1.00)$ & $0.98(0.93-1.04)$ & I.0I (0.97-I.05) \\
\hline Female & $0.97(0.95-1.00)$ & $0.99(0.94-1.05)$ & $1.01(0.99-1.02)$ & $0.99(0.93-1.04)$ \\
\hline
\end{tabular}

Notes: alschemic stroke subtyping based on classification scheme from the Trial of ORG I0I72 in Acute Stroke Treatment (TOAST); bdue to the absence of women smokers in a dataset for South Asians, no comparison was done; 'regression equation did not converge when smoking was included in the variable, small sample size-smoking was not included in the analysis.

Abbreviations: $\mathrm{Cl}$, confidence interval; $\mathrm{HDL}$, high-density lipoprotein.

not show statistically significant differential effect by sex within racial/ethnic groups. Finally, in this analysis, none of the effects for interaction terms were statistically significant, and so these terms were dropped from the final models.

\section{Conclusion}

Stroke has a greater effect on women than men due to the fact that women tend to have more stroke events and are less likely to recover from them. Studies have shown that one in six women die of stroke as compared with the one in 25 who die from cancer. ${ }^{29}$ Although age-specific stroke rates are higher in men, because of women's longer life expectancy, they suffer a much higher incidence of stroke at older ages and thus bear a heavier burden of the disease. ${ }^{5}$ There is also disparity in the mortality rates from stroke by race/ethnicity. For example, mortality for African Americans is about 33\% greater than that for Whites. ${ }^{2}$ However, few studies have compared risk factors and stroke subtypes between males and females within racial/ethnic groups.

In this study, sex comparison within racial/ethnic groups reveals that females had a greater prevalence of dyslipidemia compared with males. Except among the South Asian population, where woman had significantly higher levels of circulating blood LDL ( $\geq 100 \mathrm{mg} / \mathrm{dL}$ ) concentrations at the time of stroke presentation. The benefits of having higher HDL in circulating blood are only evident among South Asian women, where LDL and TC levels were reduced owing to a characteristic advantage of having higher levels of plasma HDL. ${ }^{26}$ This may be indicating an uncontrolled pre-stroke hypercholesterolemia among women of all racial/ethnic groups except the South Asians, a fact that was apparent by the greater incidence of ischemic and hemorrhagic stroke among hypercholesterolemic women than men.

The result of the examination of the well understood and studied stroke risk factors (hypertension, diabetes mellitus, dyslipidemia, smoking, cardiac diseases, and history of previous stroke or TIA) among our study subjects is consistent with the stroke literature. ${ }^{21,30}$ History of smoking was higher among males of all racial/ethnic groups. However, all other risk factors analyzed in this study followed a consistent pattern: a higher prevalence in White and African American females compared with their male counterparts, with the reverse trend in the South Asian and Hispanic populations. Analysis by stroke subtype shows the same group, White and African American females with South Asian and Hispanic males had a higher prevalence of ischemic stroke compared with the opposite sex within race/ethnicity. This may point to a yet unexamined or not fully understood correlation between nativity, culture, and stroke risk factors in the United States.

The regression analysis showed several significant associations between cardiovascular risk factors and ischemic stroke subtypes. However, our data showed no factors that could be consistently used to predict LAA versus SAO in acute stroke patients. The risk for LAA increased with age in White and South Asian females and in African American males. HDL proved to be a protective factor for LAA in White females but not for women in other racial/ethnic groups. A positive smoking history dramatically increased risk for LAA in White women compared with White and African American men. While our results did not demonstrate significant association between triglycerides or LDL levels 
and type of stroke, future studies with larger sample sizes may be able to elucidate the relationship between dyslipidemia and stroke subtypes.

Despite the similarity in their average ages with their sex counterparts, South Asian women and African American men were more likely to suffer from a specific etiologic type of ischemic stroke (LAA) at a younger age than previously reported. ${ }^{22}$ However, the overall result of our study was consistent with those of other studies like the Framingham Study, the Copenhagen Study, and the Israeli Heart Disease Study, which have all demonstrated a trend toward reduced risk of stroke with increasing HDL cholesterol levels in men. ${ }^{23}$ In our study, however, the increase in plasma HDL levels was more beneficial to African American women than men, while similar increases in HDL levels seem to have equal impacts on the risk of developing LAA among both sexes of South Asians. Population-based studies have shown that, overall, Blacks and men have higher TIA rates when compared with Whites and women. ${ }^{24}$ We also found that African American women had a higher proportion of patients with the incidence of TIA.

This study was limited in its ability to account for all stroke risk factors including diet, activity levels, and alcohol consumption, which may have contributed to racial/ethnic variations in the incidence of stroke. The dataset used for this study has the advantages of timeliness and quality, as well as racial/ethnic diversity. It may, however, suffer from inherent limitation of hospital-based registries in over-representing a specific racial/ethnic or socioeconomic group. That is, most of the common stroke risk factors such as hypertension, smoking, dyslipidemia, cardiac diseases, TC levels, and diabetes mellitus were also major risk factors for stroke among our racially/ethnically diverse cohort.

Our by-sex comparison showed that the prevalence of most stroke risk factors examined in this study was greater among White and African American women, South Asian and Hispanic men than their sex counterparts. We suppose that this may be a result of a confluence of factors such as lower rates of health insurance, lower utilization of health care services, or lower quality of care. The consistent pattern we observed may also be related to cultural norms and nativity, or it may reflect inherent biological differences and predisposition to disease. Future studies of racially diverse populations in different locations are needed in order to confirm these trends and begin to appropriate the relative influence of cultural and genetic factors.

Although the associations observed here do not prove causation, future prospective epidemiologic studies with diverse populations with known and suspected stroke risk factors should be conducted to adequately address important public health policy issues. These include access to both preventive and service coverage for the growing immigrant populations.

\section{Disclosure}

The authors report no conflicts of interest in this work.

\section{References}

1. Lloyd-Jones D, Adams RJ, Brown TM, et al; American Heart Association Statistics Committee and Stroke Statistics Subcommittee. Heart disease and stroke statistics - 2010 update: a report from the American Heart Association. Circulation. 2010;121(7):e46-e215.

2. Goldstein LB, Bushnell CD, Adams RJ, et al. Guidelines for the primary prevention of stroke. Stroke. 2011;42(2):517-584.

3. Roger VL, Go AS, Lloyd-Jones DM, et al. Heart disease and stroke statistics - 2012 update. Circulation. December 15, 20112011.

4. Towfighi A, Saver JL. Stroke declines from third to fourth leading cause of death in the United States: historical perspective and challenges ahead. Stroke. 2011;42(8):2351-2355.

5. Caso V, Paciaroni M, Agnelli G, et al. Gender differences in patients with acute ischemic stroke. Womens Health (Lond Engl). 2010;6(1): 51-57.

6. Di Carlo A, Lamassa M, Baldereschi M, et al. Sex differences in the clinical presentation, resource use, and 3-month outcome of acute stroke in Europe. Stroke. 2003;34(5):1114-1119.

7. Petrea RE, Beiser AS, Seshadri S, Kelly-Hayes M, Kase CS, Wolf PA. Gender differences in stroke incidence and poststroke disability in the Framingham Heart Study. Stroke. 2009;40(4):1032-1037.

8. Vaartjes I, Reitsma JB, Berger-van Sijl M, Bots ML. Gender differences in mortality after hospital admission for stroke. Cerebrovasc Dis. 2009;28(6):564-571.

9. Appelros P, Stegmayr B, Terént A. Sex differences in stroke epidemiology. Stroke. 2009;40(4):1082-1090.

10. Lambrinoudaki I, Augoulea A, Armeni E, et al. Menopausal symptoms are associated with subclinical atherosclerosis in healthy recently postmenopausal women. Climacteric. 2012;15(4):350-357.

11. Cagnacci A, Cannoletta M, Palma F, Zanin R, Xholli A, Volpe A. Menopausal symptoms and risk factors for cardiovascular disease in postmenopause. Climacteric. 2012;15(2):157-162.

12. Kwasniewska M, Pikala M, Kaczmarczyk-Chalas K, et al. Smoking status, the menopausal transition, and metabolic syndrome in women. Menopause. 2012;19(2):194-201.

13. Sirimarco G, Deplanque D, Lavallée PC, et al. Atherogenic dyslipidemia in patients with transient ischemic attack. Stroke. 2011;42(8): 2131-2137.

14. Kurth T, Everett BM, Buring JE, Kase CS, Ridker PM, Gaziano JM. Lipid levels and the risk of ischemic stroke in women. Neurology. 2007;68(8):556-562.

15. Shahar E, Chambless LE, Rosamond WD, et al. Plasma lipid profile and incident ischemic stroke. Stroke. 2003;34(3):623-631.

16. Iso H, Jacobs DR, Wentworth D, Neaton JD, Cohen JD. Serum cholesterol levels and six-year mortality from stroke in 350,977 men screened for the Multiple Risk Factor Intervention Trial. N Engl J Med. 1989;320(14):904-910.

17. Tirschwell DL, Smith NL, Heckbert SR, Lemaitre RN, Longstreth WT Jr, Psaty BM. Association of cholesterol with stroke risk varies in stroke subtypes and patient subgroups. Neurology. 2004;63(10): 1868-1875.

18. Cerrato P, Imperiale D, Fornengo P, et al. Higher lipoprotein (a) levels in atherothrombotic than lacunar ischemic cerebrovascular disease. Neurology. 2002;58(4):653-655. 
19. Smolders B, Lemmens R, Thijs V. Lipoprotein (a) and stroke. Stroke. 2007;38(6):1959-1966.

20. Adams HP Jr, Bendixen BH, Kappelle LJ, et al. Classification of subtype of acute ischemic stroke. Definitions for use in a multicenter clinical trial. TOAST. Trial of Org 10172 in acute stroke treatment. Stroke. 1993;24(1):35-41.

21. Strandgaard S. Hypertension and stroke. J Hypertens Suppl. 1996; 14(3):S23-S27.

22. Gresham GE, Kelly-Hayes M, Wolf PA, Beiser AS, Kase CS, D'Agostino RB. Survival and functional status 20 or more years after first stroke: the Framingham Study. Stroke. 1998;29(4):793-797.

23. Wannamethee SG, Shaper AG, Ebrahim S. HDL-cholesterol, total cholesterol, and the risk of stroke in middle-aged British men. Stroke. 2000;31(8):1882-1888.

24. Kleindorfer D, Panagos P, Pancioli A, et al. Incidence and short-term prognosis of transient ischemic attack in a population-based study. Stroke. 2005;36(4):720-723.
25. Kolominsky-Rabas PL, Weber M, Gefeller O, Neundoerfer B, Heuschmann PU. Epidemiology of ischemic stroke subtypes according to TOAST criteria: incidence, recurrence, and long-term survival in ischemic stroke subtypes: a population-based study. Stroke. 2001;32(12):2735-2740.

26. Fletcher B, Berra K, Ades P, et al. Managing abnormal blood lipids. Circulation. 2005;112(20):3184-3209.

27. Piechowski-Jóźwiak B, Bogousslavsky J. Cholesterol as a risk factor for stroke. Stroke. 2004;35(6):1523-1524.

28. Forster A, Gass A, Kern R, et al. Gender differences in acute ischemic stroke: etiology, stroke patterns and response to thrombolysis. Stroke. 2009;40(7):2428-2432.

29. Bousser M-G. Stroke in women: the 1997 Paul Dudley White International Lecture. Circulation. 1999;99(4):463-467.

30. Cressman M, Gifford R Jr. Hypertension and stroke. JAm Coll Cardiol. 1983;1(2):521-527. 


\section{Supplementary material}

Table SI Category of clinical characteristic measures on admission, by sex within racial/ethnic groups, in percentages

\begin{tabular}{|c|c|c|c|c|c|c|c|c|}
\hline & \multicolumn{8}{|l|}{ Sex } \\
\hline & \multicolumn{4}{|l|}{ Male } & \multicolumn{4}{|l|}{ Female } \\
\hline & \multicolumn{4}{|c|}{ Race/ethnicity } & \multicolumn{4}{|c|}{ Race/ethnicity } \\
\hline & $\begin{array}{l}\text { White } \\
(n=97 I)\end{array}$ & $\begin{array}{l}\text { African } \\
\text { American } \\
(n=36 I)\end{array}$ & $\begin{array}{l}\text { South } \\
\text { Asian } \\
(n=\mid I I)\end{array}$ & $\begin{array}{l}\text { Hispanic } \\
(n=\mid 20)\end{array}$ & $\begin{array}{l}\text { White } \\
(n=I, 185)\end{array}$ & $\begin{array}{l}\text { African } \\
\text { American } \\
(n=244)\end{array}$ & $\begin{array}{l}\text { South } \\
\text { Asian } \\
(n=162)\end{array}$ & $\begin{array}{l}\text { Hispanic } \\
(n=136)\end{array}$ \\
\hline \multicolumn{9}{|l|}{$\mathrm{TC}, \%$} \\
\hline Desirable (TC <200 mg/dL) & 67.4 & 66.4 & 68.5 & 57.4 & 61.4 & 57.3 & 68.5 & 57.5 \\
\hline Borderline high (TC $200-239$ mg/dL) & 10.8 & 14.3 & 13.0 & 11.8 & 14.5 & 19.1 & 10.8 & 19.2 \\
\hline High (TC > 240 mg/dL) & 5.1 & 5.0 & 6.8 & 7.3 & 6.8 & 9.4 & 7.2 & 9.2 \\
\hline Missing & 16.7 & 14.3 & 11.7 & 23.5 & 17.4 & 14.1 & 13.5 & 14.2 \\
\hline \multicolumn{9}{|l|}{ LDL, \% } \\
\hline Near/above optimal (LDL < 129 mg/dL) & 66.5 & 66.4 & 64.2 & 56.6 & 64.5 & 60.1 & 70.3 & 61.6 \\
\hline Borderline high (LDL I30-159 mg/dL) & II.I & 13.5 & 16.7 & 13.2 & 11.0 & 13.3 & 9.9 & 14.2 \\
\hline High (LDL 160-189 mg/dL) & 4.6 & 5.7 & 6.2 & 5.9 & 5.2 & 10.2 & 2.7 & 7.5 \\
\hline Very high (LDL $\geq 190$ mg/dL) & 2.0 & 1.6 & 1.8 & 2.2 & 2.4 & 2.5 & 4.5 & 2.5 \\
\hline Missing & 15.8 & 12.7 & II.I & 22.1 & 16.9 & 13.9 & 12.6 & 14.2 \\
\hline \multicolumn{9}{|l|}{ HDL, \% } \\
\hline Low (HDL <40 mg/dL) & 46.1 & 43.9 & 54.3 & 44.9 & 27.9 & 24.1 & 30.6 & 34.2 \\
\hline Mid-range $(40 \mathrm{mg} / \mathrm{dL} \leq \mathrm{HDL}<60 \mathrm{mg} / \mathrm{dL})$ & 32.5 & 34.8 & 30.9 & 27.2 & 40.5 & 46.3 & 46.0 & 45.8 \\
\hline High (HDL $\geq 60$ mg/dL) & 4.5 & 7.4 & 3.1 & 4.4 & 14.1 & 15.5 & 9.9 & 5.8 \\
\hline Missing & 16.8 & 13.9 & 11.7 & 23.5 & 17.5 & 14.1 & 13.5 & 14.2 \\
\hline \multicolumn{9}{|l|}{ TG, \% } \\
\hline Normal (TG $<150 \mathrm{mg} / \mathrm{dL})$ & 62.9 & 71.7 & 61.7 & 58.1 & 63.7 & 73.4 & 55.9 & 63.3 \\
\hline Borderline high (TG $150-199 \mathrm{mg} / \mathrm{dL})$ & 12.5 & 9.8 & 14.2 & 8.8 & 12.2 & 8.3 & 19.8 & 9.2 \\
\hline High (TG 200-499mg/dL) & 7.4 & 4.5 & 12.4 & 8.8 & 6.3 & 4.4 & 9.9 & 12.5 \\
\hline Very high (TG $\geq 500 \mathrm{mg} / \mathrm{dL})$ & 0.4 & 0.4 & 0.6 & 0.7 & 0.3 & 0.0 & 0.9 & 0.8 \\
\hline Missing & 16.8 & 13.5 & II.I & 23.5 & 17.5 & 13.9 & 13.5 & 14.2 \\
\hline \multicolumn{9}{|l|}{ Blood Pressure Classification, $\%^{a}$} \\
\hline Normal $(\leq 120 / 80 \mathrm{mmHg})$ & 42.5 & 31.2 & 34.6 & 38.2 & 43.8 & 37.1 & 36.0 & 42.5 \\
\hline Prehypertension (I20-139/80-89 mmHg) & 20.7 & 22.5 & 26.5 & 27.9 & 20.8 & 21.6 & 18.0 & 20.8 \\
\hline Stage I hypertension (140-159/90-99 mmHg) & 19.0 & 20.5 & 14.8 & 14.0 & 15.0 & 16.3 & 18.0 & 11.7 \\
\hline Stage 2 hypertension $(>160 / 100 \mathrm{mmHg})$ & 11.4 & 18.9 & 19.8 & 10.3 & 13.0 & 14.4 & 18.0 & 16.7 \\
\hline Missing & 6.4 & 7.0 & 4.3 & 9.6 & 7.4 & 10.5 & 9.9 & 8.3 \\
\hline \multicolumn{9}{|l|}{ Blood glucose classification, \% } \\
\hline $\mathrm{FBG}<126 \mathrm{~mm} / \mathrm{dL}^{\mathrm{c}}$ & 54.1 & 49.2 & 58.0 & 46.3 & 57.0 & 50.4 & 41.4 & 51.7 \\
\hline $\mathrm{FBG} \geq 126 \mathrm{~mm} / \mathrm{dL}$ & 35.0 & 40.2 & 35.8 & 41.2 & 31.1 & 35.7 & 46.0 & 38.3 \\
\hline Missing & 10.9 & 10.6 & 6.2 & 12.5 & 11.7 & 13.9 & 12.6 & 10.0 \\
\hline \multicolumn{9}{|l|}{$\mathrm{HbA}_{\mathrm{Ic}}$ classifications, $\% \mathrm{~b}$} \\
\hline $\mathrm{HbA}_{\mathrm{Ic}}<6.5 \%$ & 44.0 & 39.3 & 38.3 & 39.0 & 44.8 & 37.1 & 29.7 & 42.5 \\
\hline $\mathrm{HbA}_{\mathrm{Ic}} \geq 6.5 \%$ & 19.3 & 27.1 & 32.7 & 27.2 & 16.5 & 30.2 & 43.2 & 21.7 \\
\hline Missing & 36.8 & 33.6 & 29.0 & 33.8 & 38.7 & 32.7 & 27.0 & 35.8 \\
\hline \multicolumn{9}{|l|}{$\mathrm{BMI}, \%^{\mathrm{c}}$} \\
\hline Underweight $\left(\mathrm{BMI} \leq 18.5 \mathrm{~kg} / \mathrm{m}^{2}\right)$ & 0.5 & 1.6 & 1.9 & 0.0 & 3.6 & 2.5 & 4.5 & 2.5 \\
\hline Normal $\left(\mathrm{BMI}<24.9 \mathrm{~kg} / \mathrm{m}^{2}\right)$ & 29.2 & 29.2 & 49.4 & 25.0 & 35.1 & 20.2 & 36.0 & 23.3 \\
\hline Overweight $\left(25.0<\mathrm{BMI}<29.9 \mathrm{~kg} / \mathrm{m}^{2}\right)$ & 36.1 & 32.8 & 29.6 & 41.9 & 27.1 & 28.8 & 24.3 & 33.3 \\
\hline Obese $\left(\mathrm{BMI} \geq 30.0 \mathrm{~kg} / \mathrm{m}^{2}\right)$ & 24.1 & 25.8 & 14.8 & 22.8 & 22.1 & 33.8 & 19.8 & 30.8 \\
\hline Missing & 10.1 & 9.8 & 4.3 & 10.3 & 12.1 & 14.7 & 15.3 & 10.0 \\
\hline
\end{tabular}

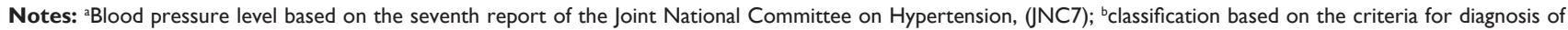
diabetes by the American Diabetes Association, 2010; 'BMI based on the Centers for Disease Control and Prevention BMI guidelines for weight status.

Abbreviations: BMI, body mass index; FBG, fasting blood glucose; $\mathrm{HbA}_{t c}$, glycated hemoglobin; HDL, high-density lipoprotein; LDL, low-density lipoprotein; TC, total cholesterol; TG, triglycerides. 
International Journal of Women's Health

Dovepress

\section{Publish your work in this journal}

The International Journal of Women's Health is an international, peerreviewed open-access journal publishing original research, reports, editorials, reviews and commentaries on all aspects of women's healthcare including gynecology, obstetrics, and breast cancer. The manuscript management system is completely online and includes Visit http://www.dovepress.com/testimonials.php to read real quotes from published authors.

Submit your manuscript here: http://www.dovepress.com/international-journal-of-womens-health-journal 